DOI: $10.47793 / \mathrm{hp} .867111$

Derleme Makalesi

Review Article

2021 - Cilt:3, Sayı:1

\title{
Depresyon ve Anksiyete Bozuklukları Üzerine Bir Bakış
}

\section{An Overview of Depression and Anxiety Disorders}

\section{Ali Yasin KAFES[1]}

Depresyon ve anksiyete toplumda en sık karşılaşılan iki hastalıktır. Bu hastalıkların beraber görülme olasılığı da oldukça yüksektir. Yapılan araştırmalarda depresyon hastalarının \%75'inde aynı zamanda anksiyete bozukluğu da olduğu tespit edilmiştir. DSM 5 ile anksiyete bozuklukları bașlığı altında birçok anksiyete hastalıkları belirlenmiștir. Depresyonun tanı grubunda yer alan semptomlara göre eşlik eden anksiyete bozukluğu da değişebilir. Bununla beraber depresyon tedavisinde eğer hastalığa anksiyete bozukluğu eşlik ediyorsa anksiyete göz ardı edilmemelidir. İlaç kullanımında sadece depresyon hastalarına göre ilacın miktarı daha fazla verilmelidir. Terapi sürecinde ise her iki hastalıkla koordineli olarak gidilmelidir. Makalenin amacı bu iki hastalık arasındaki ilişkiye literatür kapsamında ışık tutmaktır. Ayrıca hangi semptomun hangi anksiyete bozukluğu ile ilişkisi olabileceğine dair görüş bildirmektir.

Anahtar Kelimeler: major depresyon, anksiyete bozukluklarl, kaygl, duygudurum

Depression and anxiety are the two most common illnesses among the community. It is also a high possibility to face them both together. It has been determined due to researches, that $75 \%$ of the depression patients have anxiety as well. Many anxiety disorders have been defined below the Anxiety Disorders titel of DSM 5. Anxiety disorder that exists together with symptoms which takes part in the diagnosis group of depression can also change. However, if an anxiety disorder also takes part of the illness during the depression treatment, should anxiety not be undervalued. During the medicine usage, amount of the medicine should be increased only when it is due to a depression disorder. But during therapy, both disorders must be considered together. The purpose of this article is to enlighten the relationship between these disorders, under the scope of literatur. It's also aimed to remark an opinion about which symptom can be related to which anxiety disorder.

Keywords: major depression, anxiety disorders, anxiety, mood 


\section{GíRiş}

$\mathrm{D}$

epresyon ve anksiyete yüksek oranda eş tanı hastalıklardır. Depresyon hastalığının temel belirtileri depresif duygudurum ve daha önce zevk alınan aktivitelerden zevk alamamak iken, anksiyete bozukluklarının endişe ve "kara kara düşünmeye" sebep olan kaygıdır. Bunun haricinde her iki hastalıkta da uyku azalması ve artması, konstantrasyon düşüklügü, psikomotor yavaşlama, yorgunluk gibi eş belirtiler gözlenebilir (Stahl, 2013). Bu eş belirtiler her iki hastalığın komorbid şeklinde görülme sıklığını arttırmaktadır. Bu derlemenin amacı depresyon ve anksiyete bozukluklarını değerlendirip, komorbidite durumlarını değerlendirmektir.

\section{Depresyon}

Depresyon hakkındaki araştırmaların tarihine bakarsak çok eski zamanlardan bugüne süregelen bir çalışma olduğunu görebiliriz. Milattan sonra 170'li yıllarda Bergamalı tıp doktoru ve filozof olan Galen melankoliyi depresyon ve korku, diğer insanlardan nefret etmek, kişinin hayatından memnun olmaması, olarak tanımlamıştır. Ayrıca çevresel ve genetik faktörler üzerinde de durmuştur. Galen tanımlayana kadar melankoli daha çok geniş yelpazeli bir akıl hastalığı olarak tanımlanmıştır. Melankoliye hüzün ve keder anlamı yükleyen Galen olmuştur. Galen'in yanı sıra milattan sonra 1000'li yıllarda Türk-Arap dünyasında İbn-i Sina melankoli tanımı konusunda görüşlerini bildirmişlerdir. İbn-i Sina melankoliyi farklı duygudurum olarak tanımlamış ve bireyin vücudundaki sıvıların farklı oranlarda bir araya gelmesi sonucu farklı depresif durumların ortaya çlktığını söylemiştir. Bu düşüncesi ile de modern nörotransmitter varsayımının öncesi olduğu kabul edilir. 1600 'lü yıllara geldiğimizde ise Robert Burton'un yazmış olduğu Melankolinin Anatomisi adlı kitap ile melankoli, geçmiş zamanlara göre fizyolojik ağırlıklı ve bugünkü semptomlarına yakın bir şekilde tanımlanmıştır. 20. Yüzyıl başlarına gelindiğinde ise Emil Kraepelin ile melankoli depresyonun semptomu olarak tanımlanmış ve depresyona oldukça yakın bir tanım yapılmıștır. Kraepelin'e göre depresyon ana patolojinin duygudurumda çökkünlük ve fiziksel, zihinsel süreçlerde yavaşlamadır. Ancak Kraepelin'in tanımında kadınlar için menopoz sonrası erkekler için ise geç erişkinlik dönemi başlangıç olarak alınmıştır. 21. yüzyıla gelindiğinde ise teknolojik gelişmelerle beraber McLennan, Brodie, Shor, Alec Coppen gibi bilim insanlarının çalışmalarıyla monoaminler hakkındaki bilgiler arttıkça artık depresyonda varsayımlardan öte bir fizyolojik temellere dayandırılmıştır. Ayrıca psikoloji biliminde gelişen psikanalitik, davranışçı ve bilişsel bakış açıları da tanıma zenginlik katmışlardır (Yetkin ve Özgen, 2007).

Depresyon bir duygudurum bozukluğudur. Depresyon psikolojik rahatsızlıklar arasında prevalansı en yüksek hastalıklardan birisidir. Elde edilen epidemiyolojik veriler kadınların \%13'ünün, erkeklerin ise \%8'inin herhangi bir yılda depresyonda olduğunu göstermektedir. Türkiye Ruh Sağlığı Profili Çalışmasında erkeklerde \%2.3, kadınlarda \%5.4 genelde ise \%4 oranında depresif nöbet yaygınlı̆̆ı rapor etmiştir. Görüldüğü gibi kadınlarda iki kat daha fazladır (Psikofarmakoloji Bilimsel Çalışma Birimi). Genel olarak tanımı ise, kişide günlerce, aylarca belki de yıllarca süren özgüveninde azalma, yaptıklarından ve hayattan zevk alamama 
umutsuzluk ve isteksiz halinin olmasıdır. Bireylerin yașamlarına göre depresyon hastalığıyla da karşılaşma ihtimalleri değişmektedir. Kimi faktörler bu ihtimali azaltırken kimi faktörler ise ihtimali arttırmaktadır. Buna göre tıbbi hastalıklar, düşük sosyoekonomik gelir, yalnız yaşama, boşanma, işsizlik, ebeveyn, eş, çocuk kaybı, çocukluk travmaları, stresli çalışma ortamı veya aile hayatı ve madde, alkol kullanımı gibi faktörler depresyon riskini arttıran faktörlerdir. Depresyonun oldukça yaygın olması ile beraber tanısının güçlük içermesi hastalığın kronikleşme riskini doğurur. Daha da ilerleyen dönemlerde intihar ile sonuçlanabilir. Ruhsal Bozuklukların Tanısal ve İstatistiksel El Kitabı'nın beşincisinde (DSM 5) depresif bozukluklar başlığı altında birçok hastalık belirtilmiştir. Bunlar, yıkıcı duygudurum düzensizliği, major depresif bozukluk, persistan depresif bozukluk, premenstrual disforik bozukluk, madde/ilaç ilişkili depresif bozukluk, tıbbi duruma bağlı depresif bozukluk, Ayırt edilememiş depresif bozukluktur. Ancak halk arasında da depresyon olarak bilinen hastalık major depresyon başlığı ile anlatılmıştır. DSM 5’e göre major depresyon kriterleri; istek ve ilgi azalması, depresif duygudurum, uyku ve iştahta azalma veya artma, psikomotor yavaşlama, suçluluk, konsantrasyon güçlügü, enerji azalması ve intihar eğilimidir. Fakat DSM bu semptomlar arasında herhangi bir ayrım yapmamıștır. Semptomlardan bazıları normal üzüntünün de belirtisi sayılabilirken bazıları ise daha komplike bir şekilde depresyonun belirtisi sayılabilir. Bu noktada semptomların ciddiyetine göre ayrım yapılabilir. Örneğin bazı kaynaklarda komplike semptomlar olarak psikomotor yavaşlama, intihar düşüncesi, psikotik düşünce, değersizlik hissi, belirgin fonksiyonel bozukluk sayılırken, komplike olmayan semptomlar arasında üzüntü, iştahsızlık, uykusuzluk, konsantrasyon güçlüğü, yorgunluk sayılmaktadır (Wakefield ve diğ., 2017). Depresyon teşhisinde bu semptomların önceliklerini göz önünde bulundurmanın, normal üzüntü ve depresyon ayrımı yapmada önemli yeri olabilir.

Depresyona eşlik eden hem psikolojik hem de fizyolojik hastalıklar vardır. Kalp hastalığı, felç, diyabet ve Parkinson hastalığı gibi hastalıklar hem depresyona eşlik edebilen hem de depresyona sebep olabilen fizyolojik hastalıklardan bazılarıdır. Bunların yanı sıra anksiyete bozuklukları, obsesif kompulsif bozukluk, şizofreni, yeme bozuklukları, alkol ve madde bağımlılığı da depresyona eşlik eden psikolojik rahatsızlıklardandır. Depresyona eşlik eden bu hastalıklardan birisi ya da birkaçı sıklıkla depresyon ile beraber görülür. Özellikle anksiyete bozuklukları depresyon hastalarının yarısından fazlasında görülmüştür. Literatürde yapılmış olan araştırmalara baktığımızda sadece depresyon hastalığı olan bireylerin anksiyete bozukluğu da yaşadığını görmeyiz. Aynı zamanda anksiyete bozukluğu yaşayan hastaların da bu hastalıklarına depresyonun eşlik ettiğini görmekteyiz. Depresyon tanısı alan birinci basamak hastaların \%75'inin aynı zamanda bir anksiyete bozukluğu da olduğu saptanmıştır (Türkçapar, 2004). Toplumda yapılan epidemiyolojik çalışmalar temel alındığında major depresyon saptanan bir hastada ek olarak anksiyete bozukluğu gelişme riskinin 3.3 - 8.2 kat arttığı diğer yandan anksiyete bozukluğu saptanan birinin bir yıl içinde depresyon geçirme riskinin de 7-62 kat arasında yükseldiği hesaplanmıştır (Hirschfeld, 2001).

\section{Anksiyete Bozukluğu}


Anksiyete bozukluğunun epidemiyolojisine baktığımızda depresyonla neden bu kadar ilişkili olduğunu anlamaktayız. Anksiyete bozukluğunu genel olarak tanımlarsak, bireyin günlük yaşamında karşılaştığı bir durumu veya nesneyi olduğundan daha çok tehlikeli görme ve durumdan/nesneden gereğinden fazla endişelenmesi durumudur. Anksiyete hakkındaki çalışmalar bilim dünyasında uzun süredir yapılmaktadır. Özellikle ilk çalışmalar fizyolojik hastalıkların beraberinde getirmiş olduğu anksiyeteler üzerinde yapılmıştır. 1847 yılında Feuchtersleben fizyolojik hastalıkların sebep olduğu anksiyeteyi ilk kez gözlemlemiştir. Ardından 1866 yllında Morel otonomik sinir sistemindeki değişimlerin duygusal belirtilere yol açtığından söz etmiştir. 1890'lardan itibaren ise anksiyetenin birçok hastalıkla beraber gelişebilen ayrı bir ruhsal hastalık olduğu düşüncesi yaygınlaşmıştır (Berrios, 1996). 1894 yılına gelindiğinde ise Freud anksiyete nervozu terimini ortaya atmış ve psikanalitik açıdan anksiyeteyi tanımlamıştır. Freud’a göre anksiyete içgüdülerden gelen tehlikenin algılanması ile ortaya çıkmaktadır. Yani normal şartlar altında topluma uyumlu savunma mekanizmaları geliştiren ego eğer başarılı olamaz ise ortaya anksiyete çıkar. Freud'un bu tanımı ile anksiyete psikolojik boyutlarıyla da ele alınmış oldu. Yıllar içerisinde daha kapsamlı tanımları da yapılan anksiyete son olarak 1980 yılında DSM 3 ile bir hastalık olarak sınıflandırıldı. DSM 5 ile de anksiyete bozuklukları başlığı ile birçok kaygı bozukluğu tanımlanmıştır. Bu kaygı bozuklukları; yaygın aksiyete bozukluğu, seçici mutizm, özgül fobi, toplumsal kaygı bozukluğu, panik bozukluğu, agarofobi, ayrılma kaygısı bozukluğu, maddenin/ilacın yol açtığ kaygı bozukluğu, başka bir sağlık durumuna bağlı kaygı bozukluğu, tanımlanmış diğer bir kaygı bozukluğu, tanımlanmamış kaygı bozukluğudur. Anksiyete bozuklukları da depresyon gibi toplumda oldukça sık karşılaşılan hastalıklardır. DSM 5'te kaygı bozuklukları adı altında geçen tüm hastalıkların prevalans ortalamaları \%6-7 civarındadır. Ansiyete sürecinde vücudumuz bir takım fizyolojik ve psikolojik tepkiler geliştirmektedir. Çarpıntı, ağız kuruluğu, sinirlilik, kas gerilmesi, ağrı, terlemek, nefes almada güçlük çekmek, terlemek bu belirtilerden bazılarıdır.

\section{Komorbidite}

Depresyon ile anksiyete yüksek oranda birbirine eşlik eden hastalıklardır. Her iki hastalık arasında belirgin bir örtüşme vardır. Hastalar her ikisinde de aşırı endişelenme, motor gerginlik (ya da ajitasyon), uykusuzluk, çabuk yorulma ve konsantrasyon azalmasından yakınabilirler (Gülseren, 2004). Yapılan bir araştırmada depresyon tanısı almış olan hastaların \%58'inde ek tanı olarak bir anksiyete bozukluğu olduğu, anksiyete bozukluğu olan hastalarında \%68'inde ek tanı olarak depresyon hastalığı görüldüğü sonucuna ulaşılmıştır (Kessler ve ark. 1996). Ülkemizde yapılan güncel çalışmalara baktığımızda ise depresyon ve anksiyete arasında Andy Field'ın korelasyon katsayısı yorumuna göre yüksek düzey ilişki tespit edilmiştir ( $\mathrm{r}=$ 0,698, p<0.01) (Tan ve ark. 2020; Field, 2013). Yine ülkemizde ergenlerle yapılan başka bir çalışmada ise anksiyete ve depresyon arasında yüksek ilişki tespit edilmiştir ( $r=0.718$, p<0.01) (Demir ve Kumcağız, 2020). Fakat kimi hastalıklarda depresyon ön planda ve eşlik eden anksiyete arka planda kalırken kimi hastalıklarda her ikisi de ön planda olmuştur. Bununla ilgili olarak Hirschfeld'in 2001 yllında yapmış olduğu araştırmada 
depresyona eşlik eden aksiyete/anksiyeteye eşlik eden depresyon hastalarında durum dört grup olarak ayrılmıștır. Bunlar:

1- Depresyon tanısını almış olan yanı sıra tam olarak bir anksiyete bozukluğu tanısını alacak boyutta olmayan anksiyete belirtileri bulunan hastalardır.

2- Bir anksiyete bozukluğu tanısı almış olan ama yanı sıra tam bir depresif bozukluk tanısı almayacak yoğunlukta depresif belirtileri olan hastalardır.

3- Hem depresyon hem de bir anksiyete bozukluğu tanısı alabilecek yoğunlukta belirtiler gösteren hastalaridır.

4- Hem depresyon hem anksiyete belirtilerini karışık olarak gösteren ancak tek başına her iki hastalıkta da tanısal açısından eşiği geçemeyen hastalardır (Hirschfeld 2001).

Depresyonla birlikte görülen anksiyete bozukluklarının depresyonun tedavisinde göz ardı edilemez. Çünkü anksiyete bozukluğu ek tanısı alan hastalar için depresyonun süreci de değişmektedir. Her iki hastalığın da mevcut olduğu bireyler, sadece depresyon tanısı alan bireylere göre duygudurumda daha ani ve hızlı değişimlere, depreşme ve özkıyımda daha yüksek bir orana, iyileşme, hastalık gidişatında ve tedavi sürecinde daha kötü sonuçlara sahip olduğu bilinmektedir (Keller ve vd., 1983).

Depresyon hastalarında görülen semptomlar farklı anksiyete bozuklukları geliştirebilir. Depresyon hastalığının DSM 5'te geçen semptomlarına göz atacak olursak, depresif duygudurumu kişide daha çok yaygın anksiyete bozukluğuna yol açabilir. Ayrıca olumsuz duygudurumunda olan birey sosyal desteğe ihtiyacı olan bireydir. Bireyin mizacına göre değişmesiyle birlikte depresif duygudurumunda olan kişinin ailesine, arkadaşlarına karşı ayrılma kaygısı bozukluğu da geliştirmesi muhtemeldir. Olumsuz duygudurumunun getirdiği en büyük tehlikelerden birisi de alkol ve madde kullanımına sebep olabilmesidir. Birey içinde bulunduğu durumu madde veya alkol kullanarak erteleme, rahatlama yoluna gidebilir. Bu da bireyin madde/ilaç kullanımına bağlı anksiyete bozukluğu geliştirmesine sebep olabilir. İlgi ve istekte azalma durumuna da eşlik eden bazı anksiyeteler olabilir. En göze çarpanları arasında kişinin mizaç özelliğine göre geliştirdiği yaygın anksiyete bozukluğu ve toplumsal kaygı bozukluğu vardır. Psikomotor hareketlerde yavaşlama ve enerji azlığında da kişinin sosyal yaşamının sekteye uğraması kaçınılmazdır. Depresyonla beraber gelen depresif duygudurumu, enerji azalması kişinin kendini toplumdan soyutlamasına sebep olabilir. $\mathrm{Bu}$ durum süreğen bir hale geldiğinde ise kişide toplumsal kaygı bozukluğu gelişmesi kaçınılmazdır. Devam eden sürecinde ise kişinin uzun süre yalıtılmış bir hayat sürmesi çevresindeki en yakın insanlara karşı (ebeveyn, eș, çocuk) ayrılma anksiyetesi geliştirmesine de sebep olabilir. İștah ve uykuda azalma durumunda ise kişi yaygın anksiyete bozukluğu dışında panik bozukluk geliştirebilir. Vücudun homeostazi dengesinin bozulmasına neden olabilir. Ayrıca kişinin hiçbir aktiviteden zevk alamaması, uykusunun gün içerisinde çok az yr kaplaması kişide madde kullanımına sebep olabilir. Madde kullanımı ise madde/ilaç kullanımına bağlı anksiyete bozukluğuna neden olabilir. Depresyonla beraber gelen suçluluk duygusu kişinin kendisini değersiz 
görmesi ve ardından gelen intihar düşüncesine kadar gidebilir. Bu durumda birey etrafında olan biteni anlamsızlaştırabilir. Aktivitelerden ve başkalarıyla geçirilen zamandan zevk almayabilir. Bu da bireyi toplumsal anksiyete bozukluğuna, yaygın anksiyete bozukluğuna itebilir. Bununla birlikte kişide madde veya alkol kullanımı olması ya da başlaması olasıdır. Kişinin madde/ilaç kullanımına bağlı anksiyete geliştirmesi de mümkündür.

Kişi depresyon hastalığı sürecinde günlük işlevselliğini yerine getiremez. $\mathrm{Bu}$ da zaten depresif duygudurumunda olan birey için fazladan bir stres kaynağı olabilir. İşlevsellik kaybı yaşayan birey yaygın anksiyete bozukluğu dişında panik bozukluk geliştirebilir. Kişinin işlevsellik kaybı iş veya aile yaşamından olumsuz geri dönüşler almasına sebep olabileceği içinde kişinin toplumsal kaygı bozukluğu geliştirmesi oldukça olasıdır.

Depresyon ve anksiyete bozukluğu sıklıkla beraber görülen hastalıklar olmasından dolayı tedavilerinde de birbirlerinden bağımsız düşünülemezler. Depresyonda hastalığı tedavi etmek amacı ile ilaç tedavisi planlanırken eşlik eden anksiyete bozukluğu göz ardı edilmemelidir. Anksiyete bozukluğunun eşlik ettiği depresyonun tedavisinde başvurulacak yöntemler aslında depresyonu olan hastaların tedavisine oldukça benzer. Fakat anksiyete bozukluğunun eşlik ettiği depresyon hastalarında ilaç miktarının sadece depresyon hastalarında kullanılan miktardan daha fazla olması gerekmektedir. Bu hastalarda kullanılan ilacın, her iki hastalığın belirtilerini yatıștırması gerekir (Kelsey 2002). Terapi sürecinde de depresyon ve anksiyete bozukluğunun her ikisiyle de koordineli ve çözüme yönelik gidilmesi gerekir. Eğer sadece bir hastalığın tedavisine yönelik terapi süreci uygulanırsa tam bir sağlatım elde edilemez.

\section{SONUÇ VE ÖNERÍLER}

Depresyon, psikomotor yavaşlama, intihar düşüncesi, psikotik düşünce, değersizlik hissi, belirgin fonksiyonel bozukluk, üzüntü, iştahsızlık, uykusuzluk, konsantrasyon güçlüğü, yorgunluk ile karakterize iken anksiyete bozuklukları genelde endişe, uykusuzluk konsantrasyon düşüklügü, ilgisizlik, yorgunluk, panik ataklar, fobik kaçınma, sinirlilik, kas gerginliği ile karakterizedir (Wakefield, 2007; Stahl, 2013). Bu hastalıklar sıklıkla komorbid tanı alabilmektedir.

Makalede ele alınan konu hem Türk literatüründe hem de yabancı literatürde sıklıkla çalışılmıştır. Araştırma bir derleme şeklinde yapılmıştır. Gelecek araştırmalar literatürün derinlemesine taranması sonucu sistematik gözden geçirme veya meta analiz çalışmaları şeklinde yapılabilir. 


\section{KAYNAKÇA}

Amerikan Psikiyatri Birliği. (2013) Ruhsal bozuklukların tanımsal ve sayımsal $\quad$ el kitabı $\quad$ (DSM-5). (E. Köroğlu, Çev.) Hekimler Yayın Birliği.

Berrios, G. E. (1996) Anxiety and cognate disorders. Cambridge University Press.

Demir, Y. ve Kumcağız, H. (2020). Ergenlerde yeme tutum bozuklukluğunun öznel iyi oluș, depresyon, anksiyete ve stres üzerine etkisi. Uluslararası Alan Eğitimi Dergisi, 6(1), 24-36. https://doi.org/10.32570/ijofe.696583

Field, A. (2013). Discovering statistics using IBM SPSS statistics. (3. Baskı). Sage $\quad$ Publication.

Gülseren, Ș. (2004) Depresyon ve anksiyete. Klinik Psikiyatri Dergisi, Ek 1, 5-13.

Hirschfeld, R. M. (2001) The comorbidity of major depression and anxiety disorders: recognition and management in primary care. Primary Care Companion to The Journal of Clinical Psychiatry, 3, 244-254. https://doi.org/10.4088/pcc.v03n0609

Keller, M. B., Lavori, P. W., Lewis, C. E. ve Klerman, G. L. (1983). Predictors of relapse in major depressive disorder. JAMA, 250(24), 3299-3304.

Kelsey, J. E. (2002) Treatment strategies in achieving remission in major depressive disorder. Acta Psychiatry Scand, 106, 18-25.

Kessler, R. C., Nelson, C. B., McGonagle, K. A., Liu, J., Swartz, M. ve Blazer, D. G. (1996). Comorbidity of DSM-III-R major depressive disorder in the general population: results from the US National Comorbidity Survey. The British journal of psychiatry. Supplement, (30), 17-30.

Psikofarmakoloji Bilimsel Çalışma Birimi (2020, Aralık 25). Depresyon konusunda bilmek istedikleriniz. Türkiye Psikiyatri Derneği. https://www.psikiyatri.org.tr/halkayonelik/24/depresyonkonusundabilmek-istedikleriniz

Stahl, S. M. (2013). Stahl's essential psychopharmacology: neuroscientific basis and practical applications. (4. Baskı). Cambridge University Press.

Tan, M. E., Aksu, G. G. ve Toros, F. (2020). Tik bozukluğu olan çocukların sosyal fobi, $\quad$ benlik saygısı, anksiyete ve depresyon düzeylerinin değerlendirilmesi. Turk J Child Adolesc Ment Health, 27(3), 140146. https://doi.org/10.4274/tjcamh.galenos.2020.58077

Türkçapar, H. (2004). Anksiyete bozukluğu ve depresyonun tanısal ilişkileri. Klinik Psikiyatri, 4, 12-16.

Wakefield, J. C., Lorenzo-Luaces, L. ve Lee, J, J. (2007). Taking people as they are: $\quad$ evolutionary psychopathology, uncomplicated depression, and distinction between normal and disordered sadness (1. baskı) içinde (s.45-47). Cham: Springer Yayınları.

Yetkin, S. ve Özgen, F. (2007) Tarihsel bakış içinde depresyon. Türkiye Klinikleri Dahili Tıp Bilimleri Dergisi, $3(47), 1-5$. 


\section{GENișLETILMIș ÖZET}

\section{Itroduction}

Depression and anxiety disorders are highly co-diagnosed diseases. The main symptoms of depression disease are depressive mood and inability to enjoy previously liked activities, while anxiety disorders require worry and anxiety that causes "brooding". In addition, co-symptoms such as decreasing or increasing sleep, lack of concentration, slowing down of psychomotor behaviours and fatigue can be observed in both diseases (Stahl, 2013). These co-symptoms increase the incidence of both diseases in the form of comorbids. The aim of this review is to evaluate depression and anxiety disorders and to evaluate comorbidity of them.

\section{Depression}

Depression is a mood disorder and it is one of the highest prevalence of psychological disorders. Epidemiological data shows that $13 \%$ of women and $8 \%$ of men are depressed in any given year. There are different risk factors for depression such as medical conditions, low socioeconomic income, living alone, divorce, unemployment, loss of parents, spouse or child, childhood traumas, stressful work environment or family life and use of substance or alcohol. Depression is quite common, but the difficulty of diagnosis causes a risk of chronic disease. Even later, it can cause suicide. According to DSM 5, major depression criteria include decreasing desire and interest, depressive mood, decreasing or increasing sleep and appetite, slowing down of psychomotor behaviours, guilt, lack of concentration, decreasing energy and suicidal tendencies. However, the DSM does not discriminate these symptoms. Some of the symptoms can also be considered a symptom of normal sadness, while others can be considered a symptom of depression in a more complex way. At this point, the distinction can be made considering the severity of the symptoms. For instance, complex symptoms like slowing down of psychomotor behaviours, suicidal thoughts, psychotic thoughts, feelings of worthlessness are considered as explicit functional disorder, while sadness, loss of appetite, insomnia, lack of concentration and fatigue are uncomplicated symptoms in some sources (Wakefield ve diğ., 2017).

There are both psychological and physiological diseases that accompany depression. Diseases such as heart disease, stroke, diabetes and Parkinson's disease are some of the physiological diseases that can both accompany depression and also cause depression. In addition, anxiety disorders, obsessive-compulsive disorder, schizophrenia, eating disorders, alcohol and substance abuse are also psychological disorders that accompany depression.

\section{Anxiety Disorder}

Anxiety disorder can be described as a condition in which individuals perceive a situation or object that they encounter in their daily life more dangerously than it is, and they are more worried about this situation/object than necessary. Like depression, anxiety disorders are also quite common diseases in society. In DSM 5, the average prevalence of all diseases called anxiety disorders is around 6-7\%. In the process of 
anxiety, the body shows a number of physiological and psychological responses. Palpitation, dryness of the mouth, nervousness, muscle strain, pain, sweating and difficulty in breathing are some of these symptoms.

\section{Comorbidity}

Depression and anxiety are diseases that accompany highly each other. There is a marked overlap between both diseases. Patients may complain of excessive anxiety, motor tension (or agitation), insomnia, rapid fatigue, and lack of concentration in both of them. A study showed that $58 \%$ of patients diagnosed with depression had an anxiety disorder as an additional diagnosis, and 68\% of patients with anxiety disorder had depression as an additional diagnosis. (Kessler et al. 1996). When examined current studies conducted in our country, a high level of correlation was found between depression and anxiety according to Field's correlation coefficient $(r=0.698, p<0.01)$ (Tan ve ark. 2020; Field, 2013). In addition, another study conducted with adolescents in our country showed a high association between anxiety and depression $(r=0.718, p<0.01)$ (Demir ve Kumcağız, 2020). Since, for example, an individual cannot perform their daily functionality during the process of depression. This situation can be an additional source of stress for the individual who is already in a depressed mood. A person experiencing a loss of functionality may develop a panic disorder except from generalized anxiety disorder. An individual's loss of functionality can cause negative feedback from work or family life, for this reason, this person is quite likely to develop social anxiety disorder.

\section{Result}

Depression can be defined as slowing down of psychomotor behaviours, suicidal thoughts, psychotic thinking, feeling worthless, explicit functional disorder, sadness, loss of appetite, insomnia, lack of concentration and fatigue, while anxiety disorders can usually be characterized by anxiety, insomnia, low concentration, apathy, fatigue, panic attacks, phobic avoidance, nervousness and muscle strain (Wakefield, 2007; Stahl, 2013). These diseases can often be diagnosed as comorbid. 